\title{
Endophytic Epichloë species and their grass hosts: from evolution to applications
}

\author{
Kari Saikkonen $^{1}$ - Carolyn A. Young ${ }^{2}$ Marjo Helander ${ }^{1,3} \cdot$ Christopher L. Schardl $^{4}$
}

Received: 4 September 2015 / Accepted: 26 October 2015 / Published online: 5 November 2015

(c) The Author(s) 2015. This article is published with open access at Springerlink.com

\begin{abstract}
The closely linked fitness of the Epichloë symbiont and the host grass is presumed to align the coevolution of the species towards specialization and mutually beneficial cooperation. Ecological observations demonstrating that Epichloë-grass symbioses can modulate grassland ecosystems via both above- and belowground ecosystem processes support this. In many cases the detected ecological importance of Epichloë species is directly or indirectly linked to defensive mutualism attributable to alkaloids of fungal-origin. Now, modern genetic and molecular techniques enable the precise studies on evolutionary origin of endophytic Epichloë species, their coevolution with host grasses and identification the genetic variation that explains phenotypic diversity in ecologically relevant characteristics of Epichloë-grass associations. Here we briefly review the most recent findings in these areas of research using the present knowledge of the genetic variation that explains the biosynthetic pathways driving the diversity of alkaloids produced by the endophyte. These findings underscore the importance of genetic interplay between the fungus and the host in shaping their coevolution and ecological role in both natural grass ecosystems, and in the agricultural arena.
\end{abstract}

Kari Saikkonen

kari.saikkonen@luke.fi

1 Management and Production of Renewable Resources, Natural Resources Institute Finland (Luke), Itäinen Pitkäkatu 3, 20520 Turku, Finland

2 The Samuel Roberts Noble Foundation, Ardmore, OK 73401, USA

3 Section of Ecology, Department of Biology, University of Turku, 20014 Turku, Finland

4 Department of Plant Pathology, University of Kentucky, Lexington, KY 40546-0312, USA
Keywords Fungal endophytes · Grass · Genetic variation $\cdot$ Alkaloids $\cdot$ Coevolution

\section{Introduction}

Specialization and coevolution have taken the center stage of discussion in evolutionary biology since Darwin emphasized in Origin of Species how species diversity and interactions together shape the evolution of life from individuals to communities (Darwin 1859; Thompson 1994). Now we know that virtually all species evolve in interactions with other species, interactive species often reciprocally affect each other's evolution, and reciprocal changes in coevolving species often require and/or produce specialization. Thus, the majority of evolution fundamentally incorporates the elements of coevolutionary processes, and specialization commonly plays a role, especially in tightly linked species interactions such as symbiotic microbial interactions.

Interactions between endophytic Epichloë species and their host grasses provide a unique model for ecologists and evolutionary biologists interested in specialization in coevolving species interactions. By definition, fungal endophytes live internally and asymptomatically within organs of their host plant (Wilson 1995). These asymptomatic fungal infections are ubiquitous, abundant and taxonomically diverse residents in all terrestrial plants (Saikkonen et al. 1998; Rodriguez et al. 2009). The majority of endophytes are latent pathogens or dormant saprophytes and other fungal "hitch-hikers" lurking within the plant tissues without causing visible symptoms (Wilson 1995; Arnold et al. 2000; Saikkonen et al. 2004a, b; Saikkonen 2007; Rodriguez et al. 2009; Partida-Martinez and Heil 2011; Zabalgogeazcoa et al. 2013). In contrast to many other fungal taxa having asymptomatic endophytic periods in their life 
cycles, the endophytic Epichloë species (Leuchtmann et al. 2014) that are symbiotic with cool season grasses form systemic and life-long infections within their hosts. This extension of latency seen with Epichloë species is associated with reduction of virulence, adaptations and specialization that can promote fitness benefits to the host grass (Schardl 1996; Kover and Clay 1998; Saikkonen et al. 1998, 2004b, 2006, 2010a; Spatafora et al. 2007).

The symbiosis between Epichloë species and grasses is highly integrated involving the reciprocal use and manipulation of morphology, physiology, and life cycle and history traits of the partners to increase the fitness of the symbiota. First, the fungal hypha grows throughout the above-ground tissues of the host grass including inflorescences. It remains restricted to the intercellular spaces. Such an intimate relationship requires adaptations allowing the fungus to access the host plant interior, perhaps suppressing the recognition and defense responses that normally halt the establishment of harmful fungal infections in the host plant (Hamilton et al. 2012; Saikkonen et al. 2013a). The associated mechanisms are poorly understood but the oxidative balance is suggested to play a role (Hamilton et al. 2012). Second, the fitness of the partners is tightly linked, which should favor the evolution of interaction toward reduced antagonism and increased partner fidelity (Thompson 1994; Saikkonen et al. 2002).

Epichlö species are obligate associates of grasses subsisting entirely on the host grass. In addition to nutrient acquisition, grass reproduction provides a distribution avenue for the Epichloë species which are vertically transmitted in seeds from plant to its offspring. For strictly asexual Epichloë species vertical transmission is the only described means for distribution, whilst pleiotropic Epichloë species are capable of both vertical and horizontal transmission with asexual or sexual life cycles (Michalakis et al. 1992; Schardl 1996; Saikkonen et al. 1998; Tadych et al. 2012). At the other end of the continuum, truly sexual Epichlö̈ species are horizontally transmitted by ascospores. Thus, the distribution of Epichloë species is largely determined by the fitness of the host particularly in the case of strictly asexual Epichloë species (but see Saikkonen et al. 2002). In exchange for hosting the endophyte, the host grass can receive benefits such as competitive superiority compared to uninfected counterparts in a population through increased growth and reproduction, as well as resistance to various abiotic and biotic stresses such as drought, flooding, pathogens and herbivores (Clay 1988, 2009; Saikkonen et al. 2006, 2010a; Song et al. 2015). Consequently, Epichloe species have the potential to markedly affect host fitness, exert strong selective pressure on grass host traits, and modulate grassland ecosystems (Clay and Holah 1999; Saikkonen 2000; Clay et al. 2004; Rudgers et al. 2004, 2007; Saikkonen et al. 2013a).
Similarly to other biological interactions based on mutual exploitation, benefits to Epichloë species and their host grasses are rarely symmetric. Thus, the symbiosis can range from antagonistic to mutualistic, and conflicting selection forces are likely to destabilize them. For example, when pleiotropic and antagonistic Epichloë species enter their sexual life cycle they produce external stromata surrounding some or all host inflorescences eliminating seed production. The benefits from endophytes appear to be dependent on the fungal and host genotype, and on environmental conditions. Accordingly, the symbioses are commonly regarded either as commensal or mutualistic. The major destabilizing forces in the symbiosis are asymmetry in dependence and genetic compatibility. Accumulating evidence has revealed that the grass does not necessarily depend on the fungus in some environments, many Epichloë strains are host species specific and genetic mismatch between host and symbiont can limit the endophytegrass combinations (Saikkonen et al. 2004b, 2006, 2010b; Gundel et al. 2010, 2012, 2013).

In this paper we first dissect recent research advances and literature on endophytic Epichloë species, covering their evolutionary origin and taxonomical aspects, functional genetics, and coevolution with host grasses, and then examine their ecological roles and potential in novel solutions for sustainable agriculture. Accumulating findings have revealed that Epichloë species can reprogram host metabolism, and modulate photosynthesis, signaling and chemical cross-talk between the partners (Huitu et al. 2014; Eaton et al. 2010, 2015; Dupont et al. 2015) and thus, directly promote the growth, reproduction and competitive ability of the host grass (Clay and Holah 1999; Rudgers et al. 2004, 2007; Saikkonen et al. 2013b). However, here we focus on functional genetics driving alkaloid production because defense against herbivores is suggested to be the primary driving selective force behind the mutualism (Clay 2009; Saikkonen et al. 2010a).

\section{Speciation of endophytic Epichlö̈ species and their cophylogeny with grasses}

To understand the evolution of Epichloë species, it is necessary to consider the relationships of symbiont and hostplant life cycles - both sexual and asexual-and how those relate in turn to horizontal versus vertical transmission, and to haploid versus polyploid genomes.

The Epichloë species, as currently recognized by most, are systemic symbionts (or parasites) in the aerial parts of host plants in the C3 "cool season" grasses (Poaceae subfamily Pooideae), and either are choke pathogens or are related to choke pathogens (White 1993; Leuchtmann et al. 2014). Most Epichloë species can benignly colonize 
developing florets and seeds, facilitating efficient vertical transmission (Siegel et al. 1984; Tintjer et al. 2008). Horizontal transmission of some Epichloë species can occur either via asexual or sexual spores (Saikkonen et al. 2004a, b; Tadych et al. 2012). The choke pathogens can fruit on their hosts, forming a sporogenous stroma on the flag-leaf sheath and halting maturation of the subtending inflorescence ("choke" or "cattail" disease) (White 1997). The stroma produces spermatia and trichogynes (female receptive hyphae) and attracts female Botanophila sp. flies as "pollinators" that transfer spermatia. This results in crossfertilization of the A and B mating types (MTs), which are determined by the MTA and MTB idiomorphs (alternative genes or gene clusters) at the MT locus (Schardl and Scott 2012; Schardl et al. 2014). The ensuing sexual stage generates haploid spores ("ascospores") that can mediate horizontal transmission to developing seeds (Chung and Schardl 1997a) or growing plants (Meijer and Leuchtmann 1999).

In some hosts, sexual Epichloë species are observed only to transmit horizontally, but in most there can be a mixture of choked tillers and asymptomatic tillers, with the latter bearing the endophyte in the seeds (Sampson 1933; White 1994; Schardl 2001). Since there is no genetic difference in the fungus associated with choked versus asymptomatic tillers on an individual plant, it seems likely that this duality of reproductive processes has an epigenetic basis.

Most Epichloë species are incapable of fruiting on their hosts, and are therefore asexual and vertically transmitted. Some of these can still form sparse hyphal nets that produce some conidia (White et al. 1996), and theoretically could transmit horizontally as well, but vertical transmission seems by far the dominant process for asexual Epichloë species. (White et al. 1991; Moon et al. 2000, 2002; Chen et al. 2015) The majority of asexual Epichlö̈ species are diploid or triploid interspecific hybrids possessing most or all of the genomes of two or three ancestral haploids, respectively. Such polyploid, asexual hybrids seem unusual among fungi, though well documented in the Verticillium dahliae species complex (Inderbitzin et al. 2011), and a common characteristic of parthenogenic lizards, fish, amphibians (Bogart et al. 2007; Lampert and Schartl 2010; Charney 2012) and nematodes (Lunt 2008). The lack of a vegetative incompatibility system in Epichloë species (Chung and Schardl 1997b), and presumably selection favoring some hybrids over ancestral haploids can account for the abundance of hybrid Epichloë species in nature (Faeth and Saari 2012).

Investigation of possible cophylogeny of haploid Epichloë species with their pooid grass hosts would suggest when this symbiotic system first emerged. The genetic analysis of Epichloe species and grasses indicated significant host-endophyte co-divergence (Schardl et al. 2008).
Since then, an explosion of genome sequences for Epichlö̈ species and related Clavicipitaceae has allowed more detailed phylogenetic analysis (Leuchtmann et al. 2014; Schardl et al. 2014; Chen et al. 2015). Strikingly, the deepest split identified is to a clade of two species symbiotic with Achnatherum species (Fig. 1) whose tribe (Stipeae) groups in a clade that splits early from most of the other pooid tribes from which Epichloë species have been sampled (GPWG 2001). Almost as basal is the branch to $E$. glyceriae, which is associated with another early diverging tribe (Meliceae). This contrasts with a clade in most housekeeping gene trees that includes E. bromicola and E. elymi, of which the former is found in members of sister tribes Hordeeae (=Triticeae) and Bromeae, and the latter is found just in Hordeeae. Similarly, another clade encompasses several Epichloë species that are found only in Poeae; namely, E. amarillans, E. baconii, E. festucae, E. mollis and E. stromatolonga. Cophylogeny is not consistently indicated for all species and clades (particularly not for the broad host range species Epichloë typhina), but evidence of a significant tendency for co-divergence suggests that the origin of genus Epichloë may have been close in time to the origin of the highly speciose grass subfamily, Pooideae (Schardl et al. 2008; Bouchenak-Khelladi et al. 2010; Ambrose et al. 2014).

Most of but not all asexual Epichloë species are interspecific hybrids (Moon et al. 2004; Charlton et al. 2012, 2014; Iannone et al. 2012; Oberhofer and Leuchtmann 2012; McCargo et al. 2014; Schardl et al. 2012). In hosts or regions where a single hybrid Epichloë species dominates, the implication is that the product of that hybridization was an endophyte that so enhanced its host's fitness that it spread through much or all of its host's range. An example is Epichloë uncinata (E. bromicola $\times$ E. typhina subsp. poae), which is found only in the grass Lolium pratense $(=$ Schedonorus pratensis $=$ Festuca pratensis; meadow fescue), and throughout the geographical range of its host (Ekanayake et al. 2012; Karimi et al. 2012). Only one isolate from this grass has been identified as a distinct Epichloë species, E. siegelii $=E$. bromicola $\times$ E. festucae (Craven et al. 2001). Likewise, the three-part hybrid, Epichloë coenophiala, dominates populations of Lolium arundinaceum $(=$ Schedonorus arundinaceus $=$ Festuca arundinacea $;$ tall fescue) in northern Europe, central Asia (Ekanayake et al. 2012) and Iran (Karimi et al. 2012). On another continent, E. tembladerae has been found in numerous native grasses throughout Argentina (Iannone et al. 2012), including two species with a second hybrid endophyte; namely, Bromus auleticus, which can also host Epichloë pampeana (also E. festucae $\times$ typhina subsp. poae) (Iannone et al. 2009), and Phleum alpinum, which can also host Epichloë cabralii (E. typhina subsp. poae $\times$ a relative of $E$. baconii) (McCargo et al. 2014). 


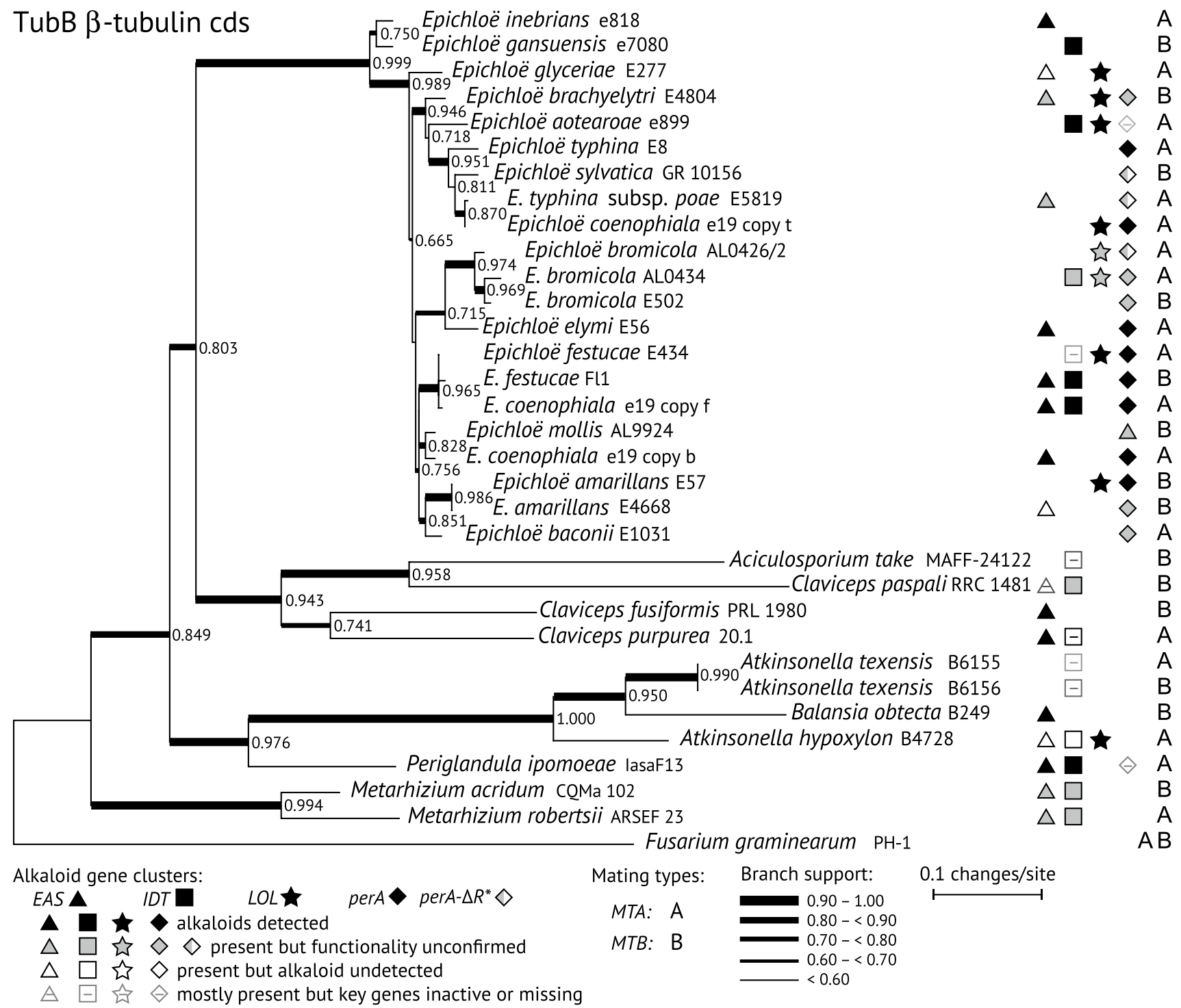

Fig. 1 Phylogeny of TubB coding sequences (cds) for Epichlö species and related species. Gene coding sequences were identified by manual annotation of sequenced genomes. The tree was inferred by maximum likelihood search using PhyML without GBlocks curation. The tree was rooted with Fusarium graminearum $\mathrm{PH}-1$ as the outgroup, and numbers on branches indicate ALR support. Alkaloid biosynthesis gene clusters and mating types are indicated after each strain designation, with symbols defined in the legends beneath the phylogram. Alkaloid gene clusters are for ergot alkaloids (EAS), indole-diterpenes (IDT) and lolines ( $L O L)$; and the multi-domain peramine synthetase gene (perA) and a related allele $\left(\operatorname{per} A-\Delta \mathrm{R}^{*}\right)$ are also indicated
Although an increasing number of studies suggest context dependency of fitness benefits to the host grass from hybrid endophytes depending on e.g. environmental conditions and cascading trophic interactions, hybrid endophytes appear to increase host adaptability especially to extreme environments (Hamilton et al. 2009, 2010; Faeth and Saari 2012; Oberhofer et al. 2014; Saari et al. 2014).

One possible reason for interspecific hybrids to provide exceptional fitness contributions to host grasses is the production of anti-herbivore alkaloids. Both $E$. coenophiala and E. uncinata, and also E. siegelii, produce very high levels of loline alkaloids, which provide broad-spectrum protection from insects (Schardl et al. 2007). Most E. coenophiala strains also produce ergot alkaloids at levels that deter grazing by livestock, as well as the insect feeding deterrent, peramine (Christensen et al. 1993; Bush et al. 1997). Many of the endophytes in Argentina have genes for indole-diterpene biosynthesis, and this fits with symptoms suffered by livestock that ingest Poa huecu, which commonly hosts E. tembladerae (Cabral et al. 1999). Such poisonings are sometimes reported to be fatal to the animal. The other Argentine endophytes, E. pampeana and $E$. 
cabralii, also produce lolines (McCargo et al. 2014). The frequency of alkaloid genes appearing in hybrids is very high, suggesting that the alkaloids constitute a significant component of the fitness enhancement that is the basis for selection of the hybrid endophytes, as discussed in the following section.

\section{Genetic diversity of Epichlö̈ species and alkaloid profile of symbiota}

The bioactive alkaloids, ergot alkaloids, indole-diterpenes, lolines and peramine, can be produced by Epichloë species and likely provide selective advantages to the host species the endophytes inhabit. The lolines are strongly insecticidal and peramine acts as an insect feeding deterrent (Siegel et al. 1990; Riedell et al. 1991). The ergot alkaloids and indole-diterpenes are most well known for their toxicity to grazing livestock in the form of fescue toxicosis and ryegrass staggers, respectively, but can also exhibit antiinsect activity.

To understand alkaloid production initial research focused on identification of pathway end products for each alkaloid class. Genetics and molecular biology were used to identify genes encoding each pathway step and recombinant technology was used to dissect the biosynthetic pathways by gene knockouts, RNAi and heterologous gene expression (Panaccione et al. 2001; Spiering et al. 2002, 2005, 2008; Wang et al. 2004; Tanaka et al. 2005; Young et al. 2005, 2006; Saikia et al. 2012; Pan et al. 2014a, b). Apart from the perA gene that encodes peramine synthetase, the other alkaloid loci (EAS for ergot alkaloids, $I D T / L T M$ for indole-diterpenes and $L O L$ for lolines) are gene clusters that are often complicated by the presence of AT-rich repetitive sequences. Genome sequencing has enlightened us on the extensive genetic diversity of Epichloë species with respect to the known alkaloids and also provides information on other biosynthetic gene clusters, for many of which the products are yet to be elucidated (Schardl et al. 2013a, b, 2014).

Comparison of gene and genome sequences from species with differing alkaloid profiles has provided insight into the genetic variation that explains endophyte chemotypic diversity (Schardl et al. 2013a, b, 2014; Berry et al. 2015). Strains of Epichloë species that are unable to produce a specific alkaloid class are typically devoid of genes encoding key pathway steps. In many cases the whole genetic locus is absent, but sometimes remnant genes, pseudogenes or gene fragments from the locus can still be identified within the genome. Chemotypic diversity within a given pathway can also be identified. For example, the chemotypic difference between two E. canadensis strains symbiotic with Elymus canadensis that vary within ergot alkaloid (chanoclavine vs. ergovaline) and loline alkaloid (1-acetamidopyrrolizidine vs. $N$-acetylnorloline) pathway end products are explained by variation of the genes that are present (Charlton et al. 2012; Schardl et al. 2013b; Pan et al. 2014a, b). The E. canadensis isolate CWR5 has a functional $E A S$ locus containing all $11 E A S$ genes enabling production of ergovaline and a $L O L$ locus for production of $\mathrm{N}$-acetylnorloline that lacks functional copies of lolP, lolM and lolN. (Note that isolates capable of producing $\mathrm{N}$-formylloline would have functional copies of lolP, lolM and $l o l N)$. The E. canadensis isolate CWR34 lacks most $E A S$ genes containing only functional copies of $d m a W$, $e a s F$, eas $C$ and easE encoding the steps for chanoclavine. The CWR34 LOL locus is similar to CWR5 except a small deletion in lolO renders the gene non-functional so the pathway stops earlier at 1-acetamidopyrrolizidine. Many other examples exist whereby the genetic variation between strains can explain differences in alkaloid chemotypes (Charlton et al. 2014; Takach and Young 2014; Young et al. 2014, 2015; Berry et al. 2015). In rare cases a whole gene cluster is present and contains no apparent deleterious mutations yet the corresponding alkaloid is not produced. It appears that these clusters are silent and gene expression is below a threshold level for functionality (Schardl et al. 2013b; Charlton et al. 2014).

Just as gene content can vary for an alkaloid locus, so can the gene arrangement within a locus. Many of the cluster rearrangements have likely occurred due to repetitive sequences within each locus. Interestingly the loci for ergot alkaloids and indole-diterpenes are located at a subterminal region of the chromosome, although the alkaloid genes located nearest the telomere can vary. The EAS clusters represent the greatest variation of cluster organization across Epichloë species with at least five different genes positioned nearest the telomere dependent on species or strain (Schardl et al. 2013a; Young et al. 2015).

The polyploid nature of the interspecific hybrid genome means that one or all ancestors can contribute alkaloid genes, which can allow for pyramiding of alkaloid classes (Fig. 2). Contributing ancestral species can be identified through phylogenetic analysis of the alkaloid genes and most often these are consistent with the species tree (Schardl et al. 2013b, Charlton et al. 2014, Berry et al. 2015). The alkaloid gene contributions in hybrid species are frequently found in the extant nonhybrid species. The chanoclavine genotype, $E A S^{C C}$, is present in the hybrids E. canadensis (hybrid of E. amarillans $\times$ E. elymi) and E. funkii $($ E. elymi $\times$ E. festucae $)$ and is contributed by $E$. elymi. There are other examples where the alkaloid gene contribution has only been found in the hybrid species and not in the extant ancestor. The $L O L$ gene origin in E. coenophiala is E. typhina subsp. poae, but $L O L$ genes are yet to be identified in this species (Kutil et al. 2007). 


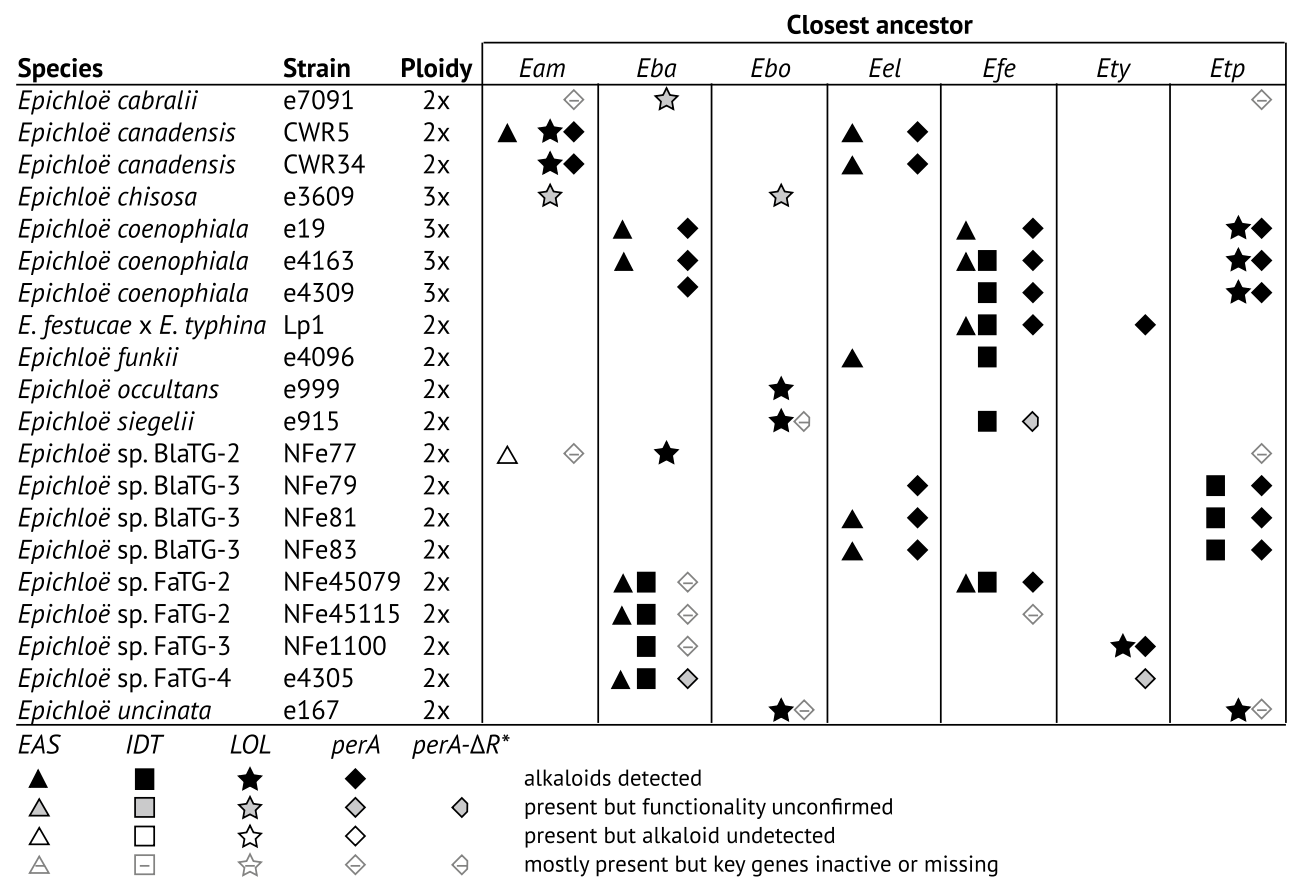

Fig. 2 Ploidy of hybrid species and closest ancestor contributing alkaloid genes. The closest ancestors are indicated as E. amarillans (Eam), E. baconii (Eba), E. bromicola (Ebo), E. elymi (Eel), E. festucae (Efe), E. typhina (Ety) and E. typhina subsp. poae (Etp). Alkaloid gene clusters are for ergot alkaloids $(E A S)$, indole-diterpenes (IDT)

In addition to alkaloid diversity, some host species are able to form a symbiotic association with different endophyte species. Tall fescue, Bromus laevipes, Elymus canadensis, Hordelymus europaeus, Achnatherum robustum and Achnatherum inebrians can independently host more than one Epichloë species but this association is still limited to only one endophyte strain per individual plant (Christensen et al. 1993; Oberhofer and Leuchtmann 2012; Schardl et al. 2013b; Charlton et al. 2014; Takach and Young 2014; Chen et al. 2015; Shymanovich et al. 2015). The symbiont variation can be further expanded due to alkaloid chemotypic variation within a single species. Conversely, sometimes the same Epichloë species can be found in diverse host species. For example E. tembladerae is recognized as a symbiont of Poa huecu, Festuca arizonica, Festuca argentina, and Bromus auleticus (Cabral et al. 1999; Moon et al. 2004; Iannone et al. 2009) but it is unknown if chemotypic variation exists across this endophyte species.

The full extent of alkaloid diversity associated with Epichloë species is only now being realized as our ability to genetically evaluate the endophyte directly within the plant has improved (Charlton et al. 2014; Takach and Young 2014; Young et al. 2014, 2015; Chen et al. 2015; Shymanovich et al. 2015). How this endophyte diversity is translated to host fitness enhancement needs to be further explored. and lolines $(L O L)$; and the multi-domain peramine synthetase gene $(\operatorname{per} A)$ and a related allele (perA- $\left.\Delta \mathrm{R}^{*}\right)$ are also indicated. Unnamed Epichloë taxa are abbreviated by host, B. laevipes Taxonomic Group (BlaTG-\#) and F. arundinacea Taxonomic Group (FaTG-\#)

\section{Ecological consequences of genetics in nature and man-made environments}

The growing literature illustrates the importance of genetics for symbiotic Epichloë species and their host grasses in both evolutionary and ecological time-scales. Phylogenetic analyses suggest the co-origin of genus Epichloë and the grass family Pooideae (Schardl et al. 2008) explaining high prevalence of Epichloë species in this particular grass family. Co-phylogeny is not consistent for all species and clades but in co-diverged phylogenetic branches hybridization is commonly detected (Moon et al. 2004; Charlton et al. 2012; Iannone et al. 2012; Oberhofer and Leuchtmann 2012; McCargo et al. 2014). Genetic compatibility between the fungal strain and the host lineage appears to play significant role in establishment of endophyte-grass combinations, and transgenerational maternal effects can affect the genetic structure of a host population (Saikkonen et al. 2010b). Genetic variation between Epichloë strains explains differences in alkaloid chemotypes (Charlton et al. 2014; Takach and Young 2014; Young et al. 2014, 2015; Berry et al. 2015) and the frequency of alkaloid genes is high in hybrids allowing for pyramiding of alkaloid classes. Thus, hybridization can result in significant fitness enhancement and selective advantage to hybrid endophytes. However, genetic differences among fungal lineages fail to 
explain for example, the duality of reproductive sexual and asexual strategies of the fungi. These observations suggest that specialization and genetic interplay between the endophyte and the host grass can largely explain phenotypic variation in the symbiotum and its ecological consequences but also suggests that other mechanisms such as phenotypic plasticity and epigenetic modifications in gene expression and function are likely to play a significant role in ecologically relevant traits of the Epichloë-grass symbiosis.

In nature, endophytic Epichloë species can affect the host growth and reproduction, the structure of grassland communities and trophic interactions, and thereby adaptive radiation of Epichloë species and their host grasses (see e.g. Clay and Schardl 2002; Clay et al. 2004; Rudgers et al. 2004, 2007; Saikkonen et al. 2004a, 2006, 2010a; Rodriguez et al. 2009). Because grasses dominate approximately $40 \%$ of the Earth's surface, Epichloë species are likely to have significant ecosystem consequences as well.

The potential applications are related to successful grass production management in the changing climate. For example, economical value of systemic grass-endophytes related to forage quality and biocontrol has already been widely recognized in agriculture and turf grass industry in the USA and New Zealand (Hoveland 1993; Gundel et al. 2013; Johnson et al. 2013). Economic losses caused by poor animal performance feeding on endophyte infected forage of tall fescue and perennial ryegrass in the United States only have been estimated at $\$ 600$ million annually (Hoveland 1993). On the other hand, fungal strains which do not produce mycotoxins harmful to cattle but increase biomass production, seed production and germination, stress tolerance (e.g. drought, flooding, temperature, and pest, pathogen and weed invasions), silicon, secondary metabolite or nutrient content should be taken into account when aiming to increase forage productivity when introduced to forage cultivars (Clay and Schardl 2002; Lehtonen et al. 2006; Saikkonen et al. 2013b; Vázquez-de-Aldana et al. 2013; Huitu et al. 2014; Song et al. 2015). One of the most successful commercial example of such an animal-safe non-toxic endophyte is "MaxQ" (E. coenophiala) in the tall fescue variety "Jesup" (Johnson et al. 2013). Examples of commercially successful novel endophytes providing bio-protective properties to the host plant against insect pests are e.g. "AR1, AR5, AR37 and NEA2" endophyte strains which have been selected and transferred to perennial ryegrass cultivars (Johnson et al. 2013). Different endophyte strains, however, exhibit remarkable variation in alkaloid types, and levels of alkaloids are context dependent (Bony et al. 2001; Johnson et al. 2013). The positive effects of endophytes appear to be more pronounced in nutrient-rich environments. Recent evidence suggests that also warming and drought stress can affect the alkaloid production of endophytes (Hill et al. 1996; Brosi et al. 2009; Compant et al. 2010) suggesting that defensive mutualism should be taken into account in grass production management in the changing climate. The associated economic and food safety profits of using these endophyte improved grass cultivars include lower investments in chemical pest control when using natural biocontrol and consumers avoid remnants of chemical pesticides in the crop, meat and milk.

Current biotechnological knowledge allows us to utilize endophytic Epichloë species in agribusiness (Gundel et al. 2013; Johnson et al. 2013). Endophytic fungi can be routinely eliminated from host plant seeds by heat treatments or fungicides and new strains introduced into the uninfected plants by inoculating the hyphae into the plant tissue. Furthermore, recent discoveries in genome mapping techniques allow identification and location of genes that encode the information that have ecological importance. In addition to enhanced mycotoxin production we are only beginning to understand genetic bases of other adaptive fungal and grass traits. This knowledge and the tools of contemporary genetics widen the possibilities of plant breeding from utilization of selected endophyteplant manipulations to the transfer of gene(s) from the fungus to grasses or other crop plants such as cereals. Thorough understanding of mechanisms underlying variation, heritability and stability of cultivar traits are, however, required to understand responses of grass cultivars to environmental change and their successful use in different environments.

\section{Conclusions and future perspectives}

The importance of endophytic Epichloë species to focal ecosystem functions driving both below- and aboveground food webs is well recognized and accepted (Omacini et al. 2001; Clay and Schardl 2002; Clay et al. 2004; Rudgers et al. 2004; Saikkonen et al. 2006, 2010a, 2013a, b, 2015; Rudgers et al. 2007; Omacini et al. 2012). Recent phylogenetic and molecular analyses coupled with accumulating ecological approaches have provided insights into the coevolution of Epichloë-grass symbiosis and how genetic interplay between the partners can have great repercussions also in a ecological time-scale. Reproduction and transmission mode (vertical vs. horizontal) of Epichloë species as well as architecture and lifespan of the host grass are important factors related to the epidemiology, genetic compatibility, specialization and evolution of avirulence in Epichloë species. However, the general questions to be solved in future studies are (a) what is the relative importance of phenotypic plasticity and heritable (genetic and/or epigenetic) variation in ecologically relevant grass traits, (b) how selection operates on the unitary, 
modular or super organism levels of Epichloë-grass associations, (c) how the phenotypic unit of the symbiotum mediates plant-plant and trophic interactions in grassland communities, and (d) species distribution ranges. Until now the lack of this knowledge has limited the use of full potential of endophytic Epichloë species in sustainable agriculture.

Acknowledgments This study was financially supported by Finnish Academy Grants 137909, 281354 and 292732, USDA-CSREES Grant 2009-34457-20125, USDA-CSREES Grant 2010-3445721269, USDA-NIFA Grant 2012-67013-19384, NSF grant EPS0814194, National Institutes of Health Grants R01GM086888 and 2 P20 RR-16481, and the Samuel Roberts Noble Foundation.

Open Access This article is distributed under the terms of the Creative Commons Attribution 4.0 International License (http://creativecommons.org/licenses/by/4.0/), which permits unrestricted use, distribution, and reproduction in any medium, provided you give appropriate credit to the original author(s) and the source, provide a link to the Creative Commons license, and indicate if changes were made.

\section{References}

Ambrose KV, Koppenhöfer AM, Belanger FC (2014) Horizontal gene transfer of a bacterial insect toxin gene into the Epichloë fungal symbionts of grasses. Sci Rep 4:5562

Arnold EA, Maynard Z, Gilbert GS, Coley PD, Kursar TA (2000) Are tropical fungal endophytes hyperdiverse? Ecol Lett 3:267-274

Berry D, Takach JE, Schardl CL, Charlton ND, Scott B, Young CA (2015) Disparate independent genetic events disrupt the secondary metabolism gene perA in certain symbiotic Epichloë species. Appl Environ Microbiol 81:2797-2807

Bogart JP, Bi K, Fu J, Noble DWA, Niedzwiecki J (2007) Unisexual salamanders (genus Ambystoma) present a new reproductive mode for eukaryotes. Genome 50:119-136

Bony S, Pichon N, Ravel C, Durix A, Balfourier C, Guillaumin J-J (2001) The relationship between myotoxin synthesis in fungal endophytes of Lolium perenne. New Phytol 152:125-137

Bouchenak-Khelladi Y, Verboom GA, Savolainen V, Hodkinson TR (2010) Biogeography of the grasses (Poaceae): a phylogenetic approach to reveal evolutionary history in geographical space and geological time. Bot J Linn Soc 162:543-557

Brosi GB, Nelson JA, McCulley RL, Classen AT, Norby R (2009) Global change factors interact with fungal endophyte symbiosis to determine tall fescue litter chemistry. The 94th ESA annual meeting

Bush LP, Wilkinson HH, Schardl CL (1997) Bioprotective alkaloids of grass-fungal endophyte symbioses. Plant Physiol 114:1-7

Cabral D, Cafaro MJ, Saidman B, Lugo M, Reddy PV, White JF Jr (1999) Evidence supporting the occurrence of a new species of endophyte in some South American grasses. Mycologia 91:315-325

Charlton ND, Craven KD, Mittal S, Hopkins AA, Young CA (2012) Epichloë canadensis, a new interspecific epichloid hybrid symbiotic with Canada wildrye (Elymus canadensis). Mycologia 104:1187-1199

Charlton ND, Craven KD, Afkhami ME, Hall BA, Ghimire SR, Young CA (2014) Interspecific hybridization and bioactive alkaloid variation increases diversity in endophytic Epichlö̈ species of Bromus laevipes. FEMS Microbiol Ecol 90:276-289
Charney ND (2012) Relating hybrid advantage and genome replacement in unisexual salamanders. Evolution 66:1387-1397

Chen L, Li XZ, Li CJ, Swoboda GA, Young CA, Sugawara K, Leuchtmann A, Schardl CL (2015) Two distinct Epichloë species symbiotic with Achnatherum inebrians, drunken horse grass. Mycologia 107:863-873

Christensen MJ, Leuchtmann A, Rowan DD, Tapper BA (1993) Taxonomy of Acremonium endophytes of tall fescue (Festuca arundinacea), meadow fescue ( $F$. pratensis), and perennial rye-grass (Lolium perenne). Mycol Res 97:1083-1092

Chung K-R, Schardl CL (1997a) Sexual cycle and horizontal transmission of the grass symbiont, Epichloë typhina. Mycol Res 101:295-301

Chung KR, Schardl CL (1997b) Vegetative compatibility between and within Epichloë species. Mycologia 89:558-565

Clay K (1988) Fungal endophytes of grasses - a defensive mutualism between plants and fungi. Ecology 69:10-16

Clay K (2009) Defensive mutualism and grass endophytes: still valid after all these years? In: Torres M, White JF Jr (eds) Defensive mutualism in symbiotic association. Taylor and Francis Publications, Oxford, pp 9-20

Clay K, Holah J (1999) Fungal endophyte symbiosis and plant diversity in successional fields. Science 285:1742-1744

Clay K, Schardl C (2002) Evolutionary origins and ecological consequences of endophyte symbiosis with grasses. Am Nat 160:s99-s127

Clay K, Holah J, Rudgers JA (2004) Herbivores cause a rapid increase in hereditary symbiosis and alter plant community composition. Proc Natl Acad Sci USA 102:12465-12470

Compant S, van der Heijden MGA, Sessitsch A (2010) Climate change effects on beneficial plant-microorganism interactions. FEMS Microbiol Ecol 73:197-214

Craven KD, Blankenship JD, Leuchtmann A, Hignight K, Schardl CL (2001) Hybrid fungal endophytes symbiotic with the grass Lolium pratense. Sydowia 53:44-73

Darwin C (1859) On the origin of species by means of natural selection, or the preservation of favoured races in the struggle for life. Facsimile of the 1st ed. Harvard University Press, Cambridge

Dupont PY, Eaton CJ, Wargent JJ, Fechtner S, Solomon P, Schmid J, Day RC, Scott B, Cox MP (2015) Fungal endophyte infection of ryegrass reprograms host metabolism and alters development. New Phytol. doi:10.1111/nph.13614

Eaton CJ, Cox MP, Ambrose B, Becker M, Hesse U, Schardl CL, Scott DB (2010) Disruption of signaling in a fungal-grass symbiosis leads to pathogenesis. Plant Physiol 153:1780-1794

Eaton CJ, Dupont PY, Solomon P, Clayton W, Scott B, Cox MP (2015) A core gene set describes the molecular basis of mutualism and antagonism in Epichloë spp. Mol Plant Microbe Interact 28(3):218-231. doi:10.1094/MPMI-09-14-0293-FI

Ekanayake PN, Hand ML, Spangenberg GC, Forster JW, Guthridge KM (2012) Genetic diversity and host specificity of fungal endophyte taxa in fescue pasture grasses. Crop Sci 52:2243-2252

Faeth SH, Saari S (2012) Fungal grass endophytes and arthropod communities: lessons from plant defence theory and multitrophic interactions. Fungal Ecol 5:364-371

GPWG (2001) Phylogeny and subfamilial classification of the grasses (Poaceae). Ann Mo Bot Gard 88:373-457

Gundel PE, Omacini M, Sadras VO, Ghersa CM (2010) The interplay between the effectiveness of the grass-endophyte mutualism and the genetic variability of the host plant. Evol Appl 3:538-546

Gundel PE, Martinez-Ghersa MA, Omacini M, Cuyeu R, Pagano E, Rios R, Ghersa CM (2012) Mutualism effectiveness and vertical transmission of symbiotic fungal endophytes in response to host genetic background Evol Appl 5:838-849 
Gundel PE, Pérez LI, Helander M, Saikkonen K (2013) Symbiotically modified organisms: non-toxic fungal endophytes in grasses. Trends Plant Sci 18:420-427

Hamilton CE, Faeth SH, Dowling TE (2009) Distribution of hybrid fungal symbionts and environmental stress. Microb Ecol 58:408-413

Hamilton CE, Dowling TE, Faeth SH (2010) Hybridization in endophyte symbionts alters host response to moisture and nutrient treatments. Microb Ecol 59:768-775

Hamilton CE, Gundel PE, Helander M, Saikkonen K (2012) Endophytic mediation of reactive oxygen species and antioxidant activity in plants: a review. Fungal Divers 54:1-10

Hill NS, Pachon JG, Bacon CW (1996) Acremonium coenophialummediated short- and long-term drought acclimation in tall fescue. Crop Sci 36:665-672

Hoveland CS (1993) Importance and economic significance of the Acremonium endophytes to performance of animals and grass plants. Agric Ecosyst Environ 44:3-12

Huitu O, Forbes KM, Helander M, Julkunen-Tiitto R, Lambin X, Saikkonen K, Stuart P, Sulkama S, Hartley S (2014) Silicon, endophytes and secondary metabolites as grass defenses against mammalian herbivores. Front Plant Sci 5:478. doi:10.3389/ fpls.2014.00478

Iannone LJ, Cabral D, Schardl CL, Rossi MS (2009) Phylogenetic divergence, morphological and physiological differences distinguish a new Neotyphodium endophyte species in the grass Bromus auleticus from South America. Mycologia 101:340-351

Iannone LJ, Novas MV, Young CA, De Battista JP, Schardl CL (2012) Endophytes of native grasses from South America: biodiversity and ecology. Fungal Ecol 5:357-363

Inderbitzin P, Davis RM, Bostock RM, Subbarao KV (2011) The ascomycete Verticillium longisporum is a hybrid and a plant pathogen with an expanded host range. PLoS One. doi:10.1371/ journal.pone. 0018260

Johnson LJ, de Bonth ACM, Briggs LR, Caradus JR, Finch SC, Fleetwood DJ, Fletcher LR, Hume DE, Johnson RD, Popay AJ, Tapper BA, Simpson WR, Voisey CR, Card SD (2013) The exploitation of epichloae endophytes for agricultural benefit. Fungal Divers 60:171-188

Karimi S, Mirlohi A, Sabzalian MR, Sayed Tabatabaei BE, Sharifnabi B (2012) Molecular evidence for Neotyphodium fungal endophyte variation and specificity within host grass species. Mycologia 104:1281-1290

Kover PX, Clay K (1998) Trade-off between virulence and vertical transmission and the maintenance of a virulent pathogen. Am Nat 152:165-175

Kutil BL, Greenwald C, Liu G, Spiering MJ, Schardl CL, Wilkinson HH (2007) Comparison of loline alkaloid gene clusters across fungal endophytes: predicting the co-regulatory sequence motifs and the evolutionary history. Fungal Genet Biol 44:1002-1010

Lampert K, Schartl M (2010) A little bit is better than nothing: the incomplete parthenogenesis of salamanders, frogs and fish. BMC Biol 8:78

Lehtonen P, Helander M, Siddiqui S, Lehto K, Saikkonen K (2006) Endophytic fungus decreases plant virus infections in meadow ryegrass (Lolium pratense). Biol Lett 2:620-623

Leuchtmann A, Bacon CW, Schardl CL, White JF, Tadych M (2014) Nomenclatural realignment of Neotyphodium species with genus Epichlö. Mycologia 106:202-215

Lunt DH (2008) Genetic tests of ancient asexuality in root knot nematodes reveal recent hybrid origins. BMC Evol Biol 8:194

McCargo PD, Iannone LJ, Vignale MV, Schardl CL, Rossi MS (2014) Species diversity of Epichloë symbiotic with two grasses from southern Argentinean Patagonia. Mycologia 106:339-352

Meijer G, Leuchtmann A (1999) Multistrain infections of the grass Brachypodium sylvaticum by its fungal endophytes Epichloë sylvatica. New Phytol 141:355-368
Michalakis Y, Olivieri I, Renaud F, Raymond M (1992) Pleiotropic action of parasites: how to be good for the host. Trends Ecol Evol 7:59-62

Moon CD, Scott B, Schardl CL, Christensen MJ (2000) The evolutionary origins of Epichloë endophytes from annual ryegrasses. Mycologia 92:1103-1118

Moon CD, Miles CO, Jarlfors U, Schardl CL (2002) The evolutionary origins of three new Neotyphodium endophyte species from grasses indigenous to the Southern Hemisphere. Mycologia 94:694-711

Moon CD, Craven KD, Leuchtmann A, Clement SL, Schardl CL (2004) Prevalence of interspecific hybrids amongst asexual fungal endophytes of grasses. Mol Ecol 13:1455-1467

Oberhofer M, Leuchtmann A (2012) Genetic diversity in epichloid endophytes of Hordelymus europaeus suggests repeated host jumps and interspecific hybridizations. Mol Ecol 21:2713-2726

Oberhofer M, Gusewell S, Leuchtmann A (2014) Effects of natural hybrid and non-hybrid Epichloë endophytes on the response of Hordelymus europaeus to drought stress. New Phytol 201(1):242-253. doi:10.1111/nph.12496

Omacini M, Chaneton EJ, Ghersa CM, Müller CB (2001) Symbiotic fungal endophytes control insect host-parasite interaction webs. Nature 409:78-81

Omacini M, Semmartin M, Pérez LI, Gundel PE (2012) Grass-endophyte symbiosis: a neglected aboveground interaction with multiple belowground consequences. Appl Soil Ecol 61:273-279

Pan J, Bhardwaj M, Faulkner JR, Nagabhyru P, Charlton ND, Higashi RM, Miller AF, Young CA, Grossman RB, Schardl CL (2014a) Ether bridge formation in loline alkaloid biosynthesis. Phytochemistry 98:60-68

Pan J, Bhardwaj M, Nagabhyru P, Grossman RB, Schardl CL (2014b) Enzymes from fungal and plant origin required for chemical diversification of insecticidal loline alkaloids in grass-Epichlö symbiota. PLoS ONE. doi:10.1371/journal.pone.0115590

Panaccione DG, Johnson RD, Wang J, Young CA, Damrongkool P, Scott B, Schardl CL (2001) Elimination of ergovaline from a grass-Neotyphodium endophyte symbiosis by genetic modification of the endophyte. P Natl Acad Sci 98:12820-12825

Partida-Martinez LP, Heil M (2011) The microbe-free plants: fact or artifact. Front Plant Sci. doi:10.3389/fpls.2011.00100

Riedell WE, Kieckhefer RE, Petroski RJ, Powell RG (1991) Naturally occurring and synthetic loline alkaloid derivatives: insect feeding behavior modification and toxicity. J Entomol Sci 26:122-129

Rodriguez RJ, White JF Jr, Arnold EA, Redman RS (2009) Fungal endophytes: diversity and functional roles. New Phytol $182: 314-330$

Rudgers JA, Koslow JM, Clay K (2004) Endophytic fungi alter relationships between diversity and ecosystem properties. Ecol Lett 7:42-51

Rudgers JA, Holah J, Orr SP, Clay K (2007) Forest succession suppressed by an introduced plant-fungal symbiosis. Ecology $88: 18-25$

Saari S, Richter S, Robbins M, Faeth SH (2014) Bottom-up regulates top-down: the effects of hybridization of grass endophytes on an aphid herbivore and its generalist predator. Oikos 123:545-552

Saikia S, Takemoto D, Tapper BA, Lane GA, Fraser K, Scott B (2012) Functional analysis of an indole-diterpene gene cluster for lolitrem B biosynthesis in the grass endosymbiont Epichloë festucae. FEBS Lett 586:2563-2569

Saikkonen K (2000) Kentucky 31, far from home. Science 287:1887

Saikkonen K (2007) Forest structure and fungal endophytes. Fungal Biol Rev 21:67-74

Saikkonen K, Faeth SH, Helander M, Sullivan TJ (1998) Fungal endophytes: a continuum of interactions with host plants. Annu Rev Ecol Syst 29:319-343 
Saikkonen K, Ion D, Gyllenberg M (2002) The persistence of vertically transmitted fungi in grass metapopulations. Proc R Soc London Ser B Biol Sci 269:1397-1403

Saikkonen K, Helander M, Faeth SH (2004a) Fungal endophytes: hitchhikers of the green world. In: Gillings M, Holmes A (eds) Plant microbiology. BIOS Scientific Publishers Limited, Oxford, pp 77-95

Saikkonen K, Wäli P, Helander M, Faeth SH (2004b) Evolution of endophyte-plant symbioses. Trends Plant Sci 9:275-280

Saikkonen K, Lehtonen P, Helander M, Koricheva J, Faeth SH (2006) Model systems in ecology: dissecting the endophyte-grass literature. Trends Plant Sci 11:428-433

Saikkonen K, Saari S, Helander M (2010a) Defensive mutualism between plants and endophytic fungi? Fungal Divers 41:101-113

Saikkonen K, Wäli P, Helander M, Faeth SH (2010b) Genetic compatibility determines endophyte-grass combinations. PLoS ONE. doi:10.1371/journal.pone.0011395

Saikkonen K, Gundel PE, Helander M (2013a) Chemical ecology mediated by fungal endophytes in grasses. J Chem Ecol 39:962-968

Saikkonen K, Ruokolainen K, Huitu O, Gundel PE, Piltti T, Hamilton CE, Helander M (2013b) Fungal endophytes help prevent weed invasions. Agric Ecosyst Environ 165:1-5

Saikkonen K, Mikola J, Helander M (2015) Endophytic phyllospere fungi and nutrient cycling in terrestrial ecosystems. Curr Sci 109:121-126

Sampson K (1933) The systemic infection of grasses by Epichlö̈ typhina (Pers.) Tul. T Brit Mycol Soc 18:30-47

Schardl CL (1996) Epichlö̈ species: fungal symbionts of grasses. Annu Rev Phytopathol 34:109-130

Schardl CL (2001) Epichloë festucae and related mutualistic symbionts of grasses. Fungal Genet Biol 33:69-82

Schardl CL, Scott B (2012) Recommendations for gene nomenclature for Epichloë species and related Clavicipitaceae. In: Young CA, Aiken GE, McCulley RL, Strickland JR, Schardl CL (eds) Epichloae, endophytes of cool season grasses: implications, utilization and biology. The Samuel Roberts Noble Foundation, Ardmore, pp 84-87

Schardl CL, Grossman RB, Nagabhyru P, Faulkner JR, Mallik UP (2007) Loline alkaloids: currencies of mutualism. Phytochemistry 68:980-996

Schardl CL, Craven KD, Speakman S, Stromberg A, Lindstrom A, Yoshida R (2008) A novel test for host-symbiont codivergence indicates ancient origin of fungal endophytes in grasses. Syst Biol 57:483-498

Schardl CL, Young CA, Faulkner JR, Florea S, Pan J (2012) Chemotypic diversity of epichloae, fungal symbionts of grasses. Fungal Ecol 5(3):331-344. doi:10.1016/J.Funeco.2011.04.005

Schardl CL, Young CA, Hesse U, Amyotte SG, Andreeva K, Calie PJ, Fleetwood DJ, Haws DC, Moore N, Oeser B, Panaccione DG, Schweri KK, Voisey CR, Farman ML, Jaromczyk JW, Roe BA, O'Sullivan DM, Scott B, Tudzynski P, An Z, Arnaoudova EG, Bullock CT, Charlton ND, Chen L, Cox M, Dinkins RD, Florea S, Glenn AE, Gordon A, Güldener U, Harris DR, Hollin W, Jaromczyk J, Johnson RD, Khan AK, Leistner E, Leuchtmann A, Li C, Liu J, Liu J, Liu M, Mace W, Machado C, Nagabhyru P, Pan J, Schmid J, Sugawara K, Steiner U, Takach JE, Tanaka E, Webb JS, Wilson EV, Wiseman JL, Yoshida R, Zeng Z (2013a) Plant-symbiotic fungi as chemical engineers: multigenome analysis of the Clavicipitaceae reveals dynamics of alkaloid loci. PLoS Genet 9(2):e1003323 doi:10.1371/journal. pgen. 1003323

Schardl CL, Young CA, Pan J, Florea S, Takach JE, Panaccione DG, Farman ML, Webb JS, Jaromczyk J, Charlton ND, Nagabhyru P, Chen L, Shi C, Leuchtmann A (2013b) Currencies of mutualisms: sources of alkaloid genes in vertically transmitted epichloae. Toxins 5:1064-1088

Schardl CL, Young CA, Moore N, Krom N, Dupont P-Y, Pan J, Florea S, Webb JS, Jaromczyk J, Jaromczyk JW, Cox MP, Farman ML (2014) Genomes of plant-associated Clavicipitaceae. Adv Bot Res 70:291-327

Shymanovich T, Saari S, Lovin ME, Jarmusch AK, Jarmusch SA, Musso AM, Charlton ND, Young CA, Cech NB, Faeth SH (2015) Alkaloid variation among epichloid endophytes of sleepygrass (Achnatherum robustum) and consequences for resistance to insect herbivores. J Chem Ecol 41:93-104

Siegel MR, Johnson MC, Varney DR, Nesmith WC, Buckner RC, Bush LP, Burrus PB II, Jones TA, Boling JA (1984) A fungal endophyte in tall fescue: incidence and dissemination. Phytopathology 74:932-937

Siegel MR, Latch GCM, Bush LP, Fannin FF, Rowan DD, Tapper BA, Bacon CW, Johnson MC (1990) Fungal endophyte-infected grasses: alkaloid accumulationand aphid response. J Chem Ecol 16:3301-3315

Song M, Li X, Saikkonen K, Li C, Nan Z (2015) An asexual Epichloë endophyte enhances waterlogging tolerance of Hordeum brevisubulatum. Fungal Ecol 13:44-52

Spatafora JW, Sung G-H, Sung J-M, Hywel-Jones NL, White JFJ (2007) Phylogenetic evidence for an animal pathogen origin of ergot and the grass endophytes. Mol Ecol 16:1701-1711

Spiering MJ, Wilkinson HH, Blankenship JD, Schardl CL (2002) Expressed sequence tags and genes associated with loline alkaloid expression by the fungal endophyte Neotyphodium uncinatum. Fungal Genet Biol 36:242-254

Spiering MJ, Moon CD, Wilkinson HH, Schardl CL (2005) Gene clusters for insecticidal loline alkaloids in the grass-endophytic fungus Neotyphodium uncinatum. Genetics 169:1403-1414

Spiering MJ, Faulkner JR, Zhang DX, Machado C, Grossman RB, Schardl CL (2008) Role of the LolP cytochrome P450 monooxygenase in loline alkaloid biosynthesis. Fungal Genet Biol 45:1307-1314

Tadych M, Abmrose KV, Bergen MS, Belanger FC, White JF Jr (2012) Taxonomic placement of Epichloë poae sp. nov. and horizontal dissemination to seedlings via conidia. Fungal Divers 54:117-131

Takach JE, Young CA (2014) Alkaloid genotype diversity of tall fescue endophytes. Crop Sci 54:667-678

Tanaka A, Tapper BA, Popay A, Parker EJ, Scott B (2005) A symbiosis expressed non-ribosomal peptide synthetase from a mutualistic fungal endophyte of perennial ryegrass confers protection to the symbiotum from insect herbivory. Mol Microbiol 57:1036-1050

Thompson JN (1994) The coevolutionary process. University of Chicago Press, London

Tintjer T, Leuchtmann A, Clay K (2008) Variation in horizontal and vertical transmission of the endophyte Epichloë elymi infecting the grass Elymus hystrix. New Phyto 179:236-246

Vázquez-de-Aldana BR, García-Ciudad A, García-Criado B, VicenteTavera S, Zabalgogeazcoa I (2013) Fungal endophyte (Epichlö̈ festucae) alters the nutrient content of Festuca rubra regardless of water availability. PLoS ONE 8(12):e84539. doi:10.1371/ journal.pone.0084539

Wang J, Machado C, Panaccione DG, Tsai HF, Schardl CL (2004) The determinant step in ergot alkaloid biosynthesis by an endophyte of perennial ryegrass. Fungal Genet Biol 41:189-198

White JF Jr (1993) Endophyte-host associations in grasses. XIX. A systematic study of some sympatric species of Epichloë in England. Mycologia 85:444-455

White JF Jr (1994) Endophyte-host associations in grasses. XX. Structural and reproductive studies of Epichloë amarillans sp. nov. and comparisons to E. typhina. Mycologia 86:571-580 
White JF Jr (1997) Perithecial ontogeny in the fungal genus Epichloë: an examination of the clavicipitalean centrum. Am J Bot $84: 170-178$

White JF Jr, Morrow AC, Morgan-Jones G, Chambless DA (1991) Endophyte-host associations in forage grasses. XIV. Primary stromata formation and seed transmission in Epichloë typhina: developmental and regulatory aspects. Mycologia 83:72-81

White JF Jr, Martin TI, Cabral D (1996) Endophyte-host associations in grasses. XXII. conidia formation by Acremonium endophytes on the phylloplanes of Agrostis hiemalis and Poa rigidifolia. Mycologia 88:174-178

Wilson D (1995) Endophyte- the evolution of a term, and clarification of its use and definition. Oikos 73:274-276

Young CA, Bryant MK, Christensen MJ, Tapper BA, Bryan GT, Scott B (2005) Molecular cloning and genetic analysis of a symbiosis-expressed gene cluster for lolitrem biosynthesis from a mutualistic endophyte of perennial ryegrass. Mol Gen Genomics 274:13-29
Young CA, Felitti S, Shields K, Spangenberg G, Johnson RD, Bryan GT, Scott B (2006) A complex gene cluster for indole-diterpene biosynthesis in the grass endophyte Neotyphodium lolii. Fungal Genet Biol 43:679-693

Young CA, Charlton ND, Takach JE, Swoboda GA, Trammell MA, Huhman DV, Hopkins AA (2014) Characterization of Epichlö̈ coenophiala within the U.S.: are all tall fescue endophytes created equal? Front Chem. doi:10.3389/fchem.2014.00095

Young CA, Schardl CL, Panaccione DG, Florea S, Takach JE, Charlton ND, Moore N, Webb JS, Jaromczyk J (2015) Genetics, genomics and evolution of ergot alkaloid diversity. Toxins 7:1273-1302

Zabalgogeazcoa I, Gundel PE, Helander M, Saikkonen K (2013) Nonsystemic fungal endophytes in Festuca rubra plants infected by Epichloë festucae in subarctic habitats. Fungal Divers 60:-2532 